\title{
Determining signals of early iron- cycling life through process-based experiments
}

\author{
JENA E. JOHNSON ${ }^{1}$, ISAAC HINZ ${ }^{1}$, ALEXIS \\ TEMPLETON $^{2}$, CHRISTINE NIMS ${ }^{1}$ AND ALICE ZHOU ${ }^{1}$ \\ ${ }^{1}$ University of Michigan \\ ${ }^{2}$ University of Colorado \\ Presenting Author: jenaje@umich.edu
}

Direct evidence of early life is likely housed in oceanic rocks composed of (bio)chemical precipitates, such as the iron- and silica-rich Archean Banded Iron Formations (BIFs). The widespread and prolonged deposition of BIFs may indicate that iron fueled the principal metabolisms on Earth before the rise of molecular oxygen. To identify signals of early iron-cycling life, we need to ascertain the original iron minerals in BIFs and establish whether their formation was mediated by biological processes. The current paradigm proposes that primary BIF minerals were Fe(III) oxides. However, new observations of iron silicate inclusions that formed before Fe(III) oxides in Archean BIF cherts challenge this hypothesis. If iron silicatesspecifically low-Fe(III) greenalite - were actually the primary iron minerals in BIFs, then the prevailing understanding of early life and the ancient iron cycle is incorrect or incomplete.

Partially oxidized iron in the BIF silicates may record early $\mathrm{Fe}(\mathrm{II}, \mathrm{III})$-cycling metabolisms, such as Fe(II)-oxidizing photosynthesis or Fe(III) respiration. We tested the role of partial iron oxidation on greenalite precipitation by adding a small proportion of ferric iron to anoxic, silica-rich artificial seawater mimicking the Archean ocean. Our results revealed that ferric iron triggers the precipitation of greenalite-like silicates, suggesting that the low-Fe(III) greenalite in Archean BIFs may signal the activity of iron-oxidizing life. We are currently exploring the precipitates produced when an iron-oxidizing phototroph mediates partial iron oxidation in simulated Archean ocean waters. Iron oxide respiration has also been proposed as an alternative explanation for early greenalite, suggesting that iron silicates are remnants of iron-reducing metabolisms. Therefore, we are performing complementary experiments with ironreducing bacteria to examine the secondary (bio)mineral products of $\mathrm{Fe}(\mathrm{III})$ oxide reduction in silica-rich conditions representative of Archean sediments.

By recreating potential Archean processes through biological and chemical laboratory experiments, we can compare the mineral products of these (bio)geochemical pathways to BIF minerals and identify what role life played in the deposition of BIFs. These emerging insights help us clarify the BIF record and its capacity to capture evidence of metabolic and biological evolution during our planet's infancy. 